\title{
Diabetes or war? Incidence of and indications for limb amputation in Lebanon, 2007
}

\author{
K. Yaghi, ${ }^{1}$ Y. Yaghi, ${ }^{2}$ A.A McDonald,,$^{3,4}$ Gh. Yadegarfar, ${ }^{3}$ E. Cecil, ${ }^{3}$ J. Seidl, ${ }^{3}$ E. Dubois ${ }^{3}$, S. Rawaf ${ }^{3}$ and A. Majeed ${ }^{3}$
}

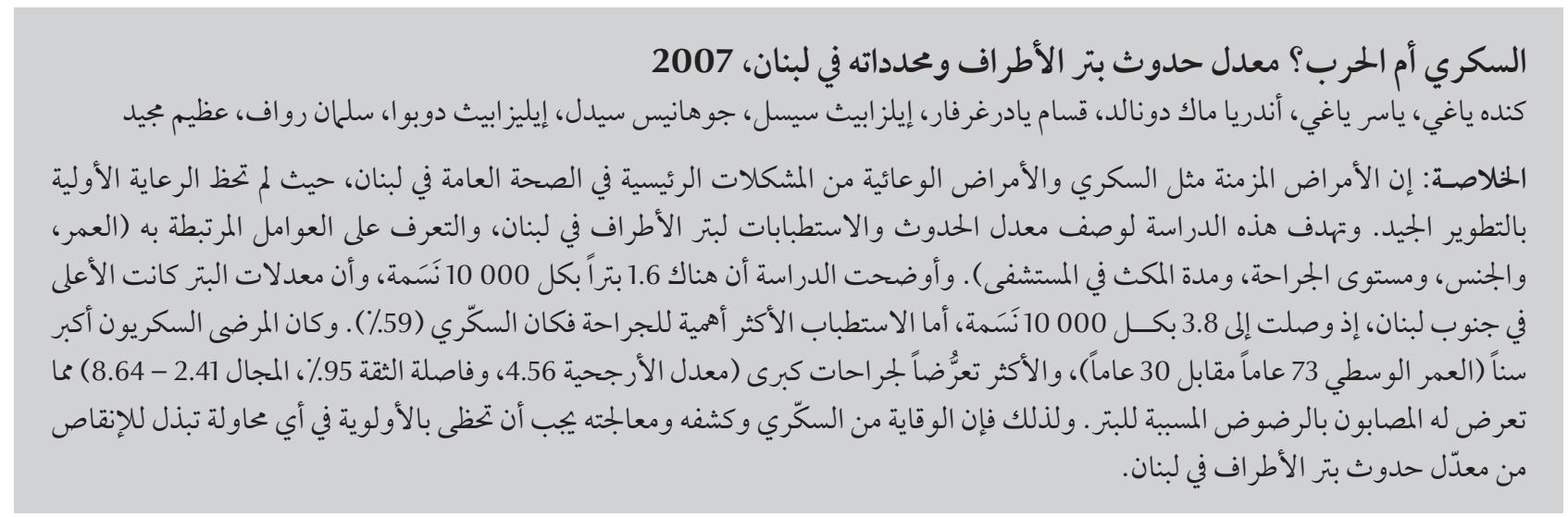

ABSTRACT Chronic diseases such as diabetes and vascular disease are a major public health problem in Lebanon, where primary care is not well developed. This study aimed to describe the incidence and indications for limb amputation in Lebanon and identify associated factors (age, sex, level of surgery, length of hospital stay). There were 1.6 amputations per 10000 persons. The rate of amputation was highest in southern Lebanon at 3.8 per 10 000. The most important indication for surgery was diabetes (59\%). Diabetic patients were older (mean age 73 years versus 30 years), more likely to have major surgery $(\mathrm{OR}=7.87 ; 95 \% \mathrm{Cl}: 2.83-21.9)$ and stay in hospital longer $(\mathrm{RR}=4.56,95 \% \mathrm{Cl}: 2.41-8.64)$ than patients with trauma-related amputation. Diabetes prevention, detection and management should be prioritized in any attempt to reduce the current incidence of amputation in Lebanon.

\section{Diabète ou guerre ? Incidence et indications des amputations au Liban en 2007}

RÉSUMÉ Des maladies chroniques telles que le diabète et les maladies vasculaires sont un problème de santé publique majeur au Liban, où les soins de santé primaires ne sont pas bien développés. L'étude visait à décrire l'incidence et les indications des amputations au Liban et à déterminer les facteurs associés (âge, sexe, niveau de chirurgie, durée de l'hospitalisation). L'étude a comptabilisé 1,6 amputation pour 10000 personnes. Le sud du Liban présentait le taux d'amputation le plus élevé avec 3,8 amputations pour 10 000. Le diabète était l'indication la plus importante pour une chirurgie (59\%). Les patients diabétiques étaient plus âgés (âge moyen 73 ans par rapport à 30 ans), étaient plus susceptibles de subir une intervention chirurgicale importante (OR = 7,87 ; IC à $95 \%$ : 2,83-21,9) et de séjourner plus longtemps à l'hôpital (RR = 4,56 ; IC à $95 \%$ : 2,41-8,64) que les patients ayant eu une amputation suite à un traumatisme. La prévention du diabète, son dépistage et sa prise en charge doivent devenir prioritaires afin de tenter de réduire l'incidence actuelle des amputations au Liban.

${ }^{7}$ Bone and Joint Decade, Beirut, Lebanon.

${ }^{2}$ Department of Orthopaedic Surgery, Hammoud Hospital University Medical Center, Beirut, Lebanon.

${ }^{3}$ Department of Primary Care and Public Health, Imperial College London, London, United Kingdom (Correspondence to S. Rawaf: s.rawaf@ imperial.ac.uk).

${ }^{4}$ Department of Biostatistics, Kermanshah University of Medical Sciences, Kermanshah, Islamic Republic of Iran.

Received: 28/08/11; accepted: 12/12/11 


\section{Introduction}

Historically, the major causes for limb amputation have been injuries resulting from accidents or war. Yet the rising incidence of diabetes and vascular disease worldwide is being reflected in the greater incidence of type 2 diabetes-related amputations; for example, the rate increased from 2.0 to 2.7 per 100000 population in England between 1996 and 2005 [1]. In Lebanon, the prevalence of type 2 diabetes was $13.1 \%$ for those aged 30+ years in 1994-95 [2] and this is likely to have increased. It is estimated that the prevalence of diabetes in Lebanon will increase from $13.7 \%$ in 1995 to $18.0 \%$ in 2025 for those aged $20+$ years [3].

Diabetes leads to complications such as angiopathy and neuropathy, which themselves lead to ischaemia, ulceration and poorly healing infections. Other factors leading to micro- and macro-angiopathy include smoking, obesity, hypercholesterolaemia, hyperlipidaemia, vasculitis and high blood pressure and these risk factors appear to be an increasing problem in the Eastern Mediterranean region [4]. Two or more of these risk factors exponentially increases the possibility of arterial occlusion and amputation. Sedentary lifestyle and excess calorie intake of energy-rich foods are well-known risk factors for both diabetes and cardiovascular disease.

According to the Rights and Access Programme at the Ministry of Social Affairs, amputation is responsible for around one-tenth of impairments in Lebanon. Immediately after the 1975 civil war in Lebanon, disability due to war injuries became a key public health concern. Lebanon is considered one of the most heavily land-mined countries in the world. Data obtainable from the disability programme at the Ministry of Social Affairs confirms that there are a total of 56391 disabled persons that have been registered since the development of the national de-mining programme in the late 1990s [5]. The Bone and Joint Decade held the first Lebanese National Forum on Amputation on 29 April 2006 [6]. Its main aim was to highlight the major burden of amputation and to set standards for data collection. A target of the Forum was to gather data on all amputation cases in Lebanon including the surgical indications so that a better understanding of the scope of the problem could be achieved in order to support the development of programmes for amputation prevention and care. The analysis presented here draws on the data collected as a result of the Forum.

The aims of this study were to use the Lebanon national database to assess the incidence of limb amputations in 2007 , nationally and by region; to describe the indications for amputation; to describe the demographic characteristics of amputation patients; and to investigate how amputation was associated with age, sex, level of surgery and length of hospital stay.

\section{Methods}

\section{Data sources}

After the first Forum on Amputation in Lebanon, the Minister of Health circulated an alert asking hospitals in Lebanon to report every case of amputation during 2007 to the office of the Lebanese National Programme for Prevention of Accidents and Injuries. Permission was granted by the Ministry of Public Health $(\mathrm{MoPH})$ and the Lebanon Bone and Joint Decade, $\mathrm{Na}$ tional Action Network for the release of this data to be analysed in this research project.

\section{Data collection}

From January 2007 to December 2007, all admissions to 92 hospitals that resulted in amputation were included in the data. Each patient's hospital records were examined and data was extracted on to a standardized form including age, sex, name of the hospital, admission and discharge dates, indication for surgery and the level of amputation. Indication was defined as the cause (clinical reason) for surgery according to the patient's hospital record. Level was assigned by standardized hospital codes and categorized as femur, tibia, foot or upper limb and whether it was major (above the ankle or above the wrist) or minor (hand, foot or part thereof). One main indication was recorded for each patient from either trauma, diabetes, vascular or other. The accreditation of each hospital was added to the data [7]. Where any aspect of a data record was missing, contact was made with the hospital to verify the missing details.

Both the national and regional rates of amputation were calculated from the 2007 national population $(4.16$ million) from the United Nations Food and Agriculture Organization website [8] and the 2004-05 regional populations from the Central Administration for Statistics of the Ministry of Social Affairs for Lebanon and United National Development Programme (UNDP) [9]. Incidence rates were unadjusted and $95 \%$ confidence intervals (CI) were calculated (with direct standardization) to compare estimates of amputation rate across the regions.

\section{Statistical analysis}

The analysis was carried out using Stata $S E$, version 11.0 software. Results were tabulated and associations with indication and other variables were initially examined using the chi-squared test. Both medians and geometric means were used to describe length of hospital stay, in order to take into account the skewed nature of the data.

Logistic regression was applied to investigate the association between indication and the level of surgery. Age- and sex-adjusted odds ratios (OR) were estimated with 95\% confidence intervals (CI). In adjusting for confounders, age was categorized into $<30,30-49,50-64,65-79$ and 80+ 


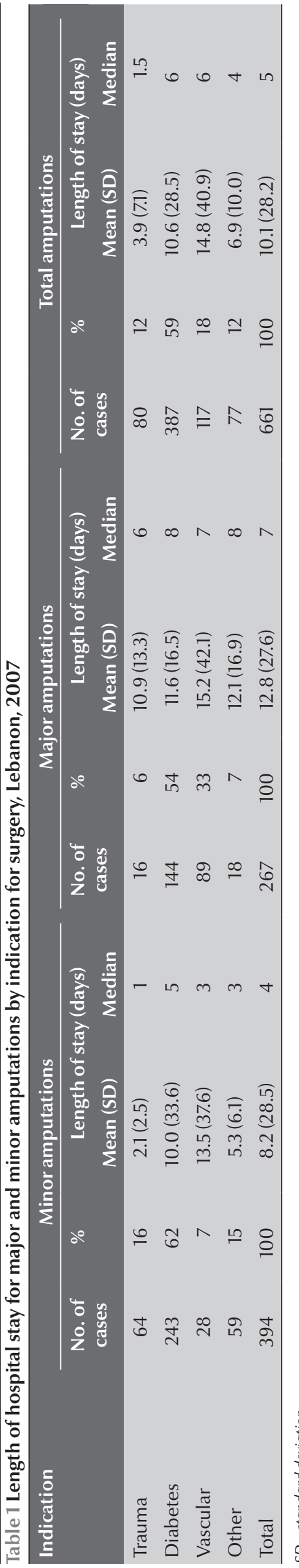

years, to maintain adequate numbers in each strata. Diabetes, vascular and other indications were compared with trauma-related amputation.

Poisson regression with scaled deviance to correct inadequate fit from over dispersion was used to investigate the association between indication and the length of hospital stay, adjusting for age and sex. Similarly, level of surgery was examined for its association with hospital length of stay, adjusting for indication, age and sex.

\section{Results}

\section{Incidence}

During 2007, there were $661 \mathrm{limb}$ amputations identified. Of these 267 (40\%) were major level amputations and $394(60 \%)$ were minor amputations, while 574 (87\%) were lower limb amputations (Table 1). The rate for all types of amputation was 1.76 per 10000 persons, and the rate of lower extremity amputation was 1.40 per 10000 . The rate for major amputations was 0.64 per 10000 persons and the rate for minor amputations was 0.95 per 10000 . There was variation across the regions, with southern Lebanon recording the highest amputation rate at 3.82 per 10000 persons (Table 2).

Diabetes was the indication for $59 \%$ of the amputations, vascular disease for $18 \%$ and trauma for $12 \%$ (Table 3 ). Indications for surgery were similar across all regions, including southern Lebanon where trauma, diabetes and vascular disease amputations all occurred at more than twice the national rate (Table 2).

\section{Age and sex}

The mean age of amputation patients was 63 (SD 21) years and 66\% were male (Table 3). There was strong evidence $\left(\chi^{2}\right.$-test, $\left.P<0.001\right)$ that patients with different indications for surgery had different age distributions (Figure 1). For example $70 \%$ of diabetic patients were aged $70+$ years, compared with $4 \%$ of trauma patients. The mean age was 73 (SD 10) years for diabetic amputations, 63 (SD 12) years for vasculopathy and 30 (SD 18) years for trauma. Males comprised a higher proportion of trauma-related amputation patients than in other indication groups ( $86 \%$ versus $61 \%-64 \%)\left(\chi^{2}\right.$-test, $P<0.001)$.

\section{Major level surgery}

Over two-thirds of trauma patients (69\%) had upper limb amputations, whereas this was rare for vascular and diabetic patients (1\% and 3\% respectively) ( $\chi^{2}$-test, $P<0.001$ ). Although $40 \%$ of all amputations were major level, this differed significantly across different indications; $20 \%$ of traumarelated amputations were major, $37 \%$ of diabetes-related and $76 \%$ of vascularrelated $\left(\chi^{2}\right.$-test, $\left.P<0.001\right)$ (Table 1 ). Thus, compared with patients with trauma-related amputations, those with diabetes had higher odds of major level surgery $(\mathrm{OR}=2.37 ; 95 \% \mathrm{CI}: 1.32-4.26)$ and those with vascular indications had even higher risk of major surgery $(\mathrm{OR}=$ 12.7; 95\% CI: 6.36-25.4). When these figures were adjusted for age and sex, the estimated odds ratios increased substantially $(\mathrm{OR}=7.87$; 95\% CI: $2.8-21.9$ and $\mathrm{OR}=46.3,95 \% \mathrm{CI}: 15.9-134$ respectively).

\section{Length of hospital stay}

The geometric mean length of hospital stay for all patients was 5.2 days. Amputations following diabetes and vascular disease were associated with the longest length of hospital stay (geometric mean 4.7 and 4.9 days respectively) compared with trauma cases (1.8 days). Patients with minor level amputations had shorter mean hospital stays (3.9 days) than those with major level amputations (5.8 days). Patients with diabetes and vascular indications for surgery had 4.56 and 6.33 times respectively longer hospital stays compared with patients with trauma. Independent of 


\begin{tabular}{|c|c|c|c|c|}
\hline Region & No. of cases & Population $^{\mathrm{a}}$ & $\begin{array}{l}\text { Amputation rate per } \\
10000\end{array}$ & $95 \% \mathrm{Cl}$ \\
\hline Mount Lebanon & 164 & 1501570 & 1.09 & $0.97-1.21$ \\
\hline South Lebanon & 238 & 622683 & 3.82 & $3.48-4.17$ \\
\hline Beirut & 50 & 390503 & 1.28 & $1.03-1.53$ \\
\hline Bekaa & 76 & 471209 & 1.61 & $1.36-1.87$ \\
\hline North Lebanon & 133 & 768709 & 1.73 & $1.52-1.94$ \\
\hline Total & 661 & 3755034 & 1.76 & $1.63-1.89$ \\
\hline
\end{tabular}

${ }^{a}$ Source: [9].

$\mathrm{Cl}=$ confidence interval.

Table 3 Age, sex, indication for surgery, level and length of hospital stay of patients undergoing limb amputation, Lebanon, 2007

\begin{tabular}{|c|c|}
\hline Variable & $\begin{array}{c}\% \text { of cases } \\
(n=661)\end{array}$ \\
\hline \multicolumn{2}{|l|}{ Indication for surgery } \\
\hline Diabetes & 59 \\
\hline Vasculopathy & 18 \\
\hline Trauma & 12 \\
\hline Uncontrollable infection & 7 \\
\hline Tumour & 2 \\
\hline Congenital deformity & 1 \\
\hline Other (scleroderma, Buerger disease, rheumatic diseases) & 1 \\
\hline \multicolumn{2}{|l|}{ Age (years) } \\
\hline $0-19$ & 6 \\
\hline 20-39 & 8 \\
\hline $40-59$ & 17 \\
\hline $60-79$ & 50 \\
\hline $80+$ & 18 \\
\hline \multicolumn{2}{|l|}{ Sex } \\
\hline Male & 66 \\
\hline Female & 34 \\
\hline \multicolumn{2}{|l|}{ Limb level } \\
\hline Upper limb & 13 \\
\hline Foot and toes & 47 \\
\hline Tibia & 22 \\
\hline Femur & 18 \\
\hline \multicolumn{2}{|l|}{ Level of surgery } \\
\hline Minor & 60 \\
\hline Major & 40 \\
\hline \multicolumn{2}{|l|}{ Length of hospital stay (days) } \\
\hline $0-1$ & 14 \\
\hline $2-4$ & 29 \\
\hline $5-7$ & 24 \\
\hline $8-14$ & 19 \\
\hline $15+$ & 14 \\
\hline
\end{tabular}

the indication for surgery, age and sex, patients with major surgery still had a small but statistically significant $26 \%$ increase in length of hospital stay [adjusted relative risk $(\mathrm{RR})=1.26$; $95 \% \mathrm{CI}$ : 1.01-1.57] (Table 4).

\section{Missing data}

Our nationwide study included 92 of 126 accredited hospitals, 55 of them had available amputation data and 37 did not perform amputations, but still responded to the $\mathrm{MoPH}$ order, contributing to a response rate of $73 \%$. Half of the amputations ( $51 \%$ ) were performed in top accredited hospitals (rated level 1, reflecting the highest standards) and $36 \%$ were in level 2 (out of a possible 4 levels).

\section{Discussion}

\section{Strengths and limitations}

The data collected by the MoPH provided an excellent overall picture of amputation in Lebanon. The results came from a wide range of regions and there was a good response, from almost three-quarters of hospitals. Those hospitals which did not submit data were evenly spread across the country and were expected to mainly comprise smaller hospitals that did not perform major amputation surgery. Missing responses highlight that not all hospitals had thus far fully computerized their data. Manual data entry leads to organizational challenges and multiple errors. 


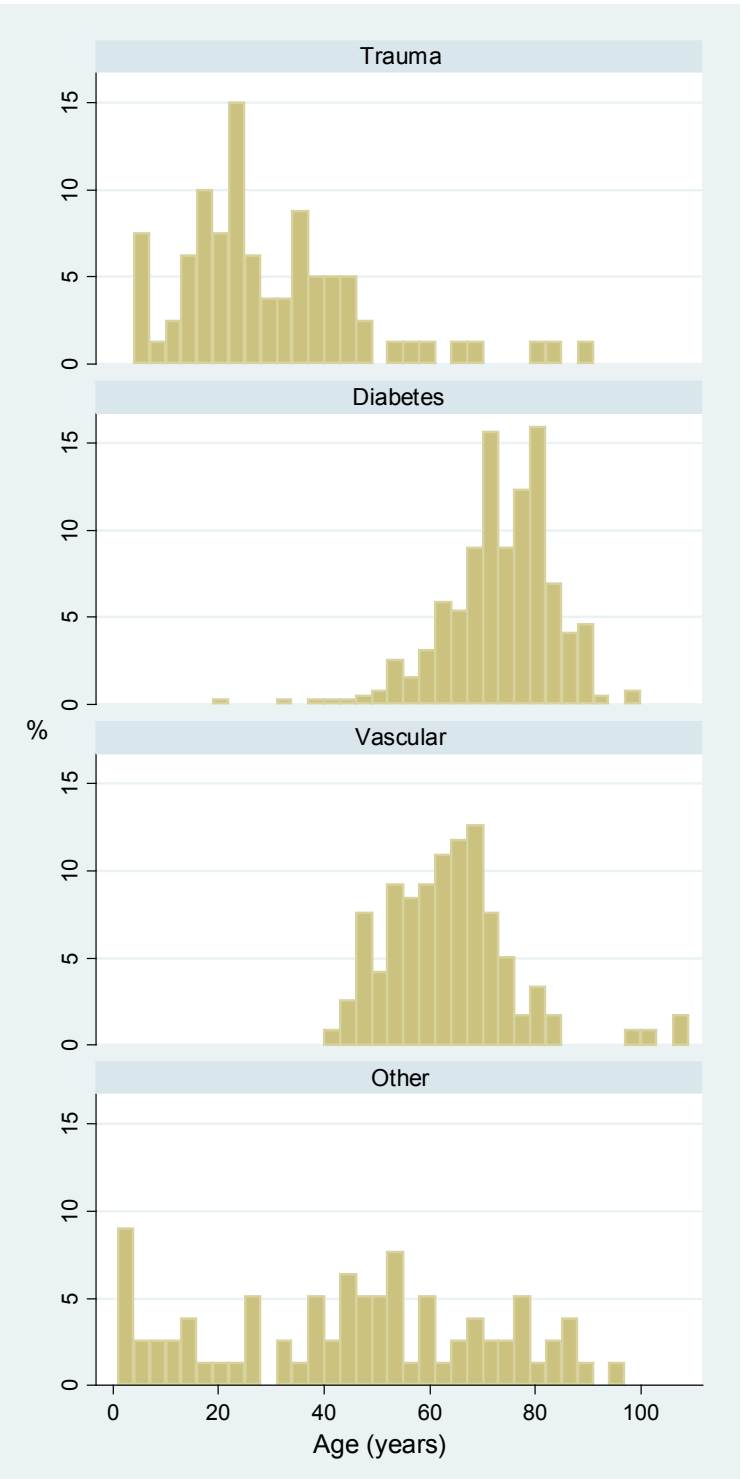

Figure 1 Age distribution of limb amputation patients by indication for surgery, Lebanon, 2007

However, all the large main hospitals and university hospitals did contribute to our data. The files received from participating hospitals included very little missing data. For any patient that had missing codes or age data the hospital was contacted to elucidate missing values. A small number of patients with incomplete data were omitted from the analysis. Our incidence of amputation is therefore likely to be an underestimate of the true rate. Not only were there some hospitals that did not provide data, but the hospitals that did may not have included all the eligible minor amputations [5]. Thus it is possible that trauma was underestimated as an indication, especially for minor amputations.

Our figures were also limited in that we were unable to allow for multiple indications for an individual patient. Ideally, multiple comorbidities would be recorded so that a patient undergoing amputation can be registered as having both diabetes and vascular disease. In our data, it is uncertain whether one indication was recorded in preference to another. Diabetes may have been considered the preferred indication if it were diagnosed; however it is possible that some hospitals may have taken a different approach. The presence of any bias from overlap of indications is only likely to underestimate the impact of diabetes on amputation and will not impact on our conclusions.

A more in-depth analysis would have been possible if data were available on socioeconomic status and education for individual patients. Confounders could have been adjusted for and any distinguishing disparities could be identified and better understood, especially between regions. It was not the main focus of this cross-sectional analysis, however, to answer questions about inequality.

Amputation incidence from a cross-sectional survey does not give a meaningful picture of the ongoing burden of disease from amputation, i.e. the prevalence of patients living with previous amputation. To document the prevalence of amputation a community-based survey would be more appropriate and this might include questions that address the ongoing functional, social and economic impact of amputation. Variables such as mortality and quality of life would enable a better understanding of the ongoing impact of amputation.

\section{Incidence}

Taking into account that our amputation incidence of 1.76 per 10000 was likely to be an underestimate and may have been higher if all hospitals responded; this rate is not especially high compared with developed countries. Our incidence for lower extremity amputation of 1.4 per 10000 population falls in the middle range of a 10-centre study [10]. Our diabetes-related amputation rate of 0.9 per 10000 population is much less that the rates if $2.8-43.9$ per 10000 population in one review from the 1990s [11] and less than 


\begin{tabular}{|c|c|c|c|c|}
\hline \multirow[t]{2}{*}{ Variable } & \multirow[t]{2}{*}{$\begin{array}{l}\text { No. of } \\
\text { cases }\end{array}$} & Length of stay & $\begin{array}{c}\text { Length of stay } \\
\text { (adjusted for age, sex) }\end{array}$ & $\begin{array}{l}\text { Length of stay (adjusted for } \\
\text { indication, age, sex) }\end{array}$ \\
\hline & & RR $(95 \% \mathrm{Cl})$ & $\operatorname{aRR}(95 \% \mathrm{CI})$ & $\operatorname{aRR}(95 \% \mathrm{CI})$ \\
\hline \multicolumn{5}{|c|}{ Indication for surgery } \\
\hline Trauma & 80 & 1 & 1 & - \\
\hline Diabetes & 387 & $2.74(1.67-4.50)$ & $4.56(2.41-8.64)$ & - \\
\hline Vascular & 117 & $3.84(2.29-6.45)$ & $6.33(3.35-12.0)$ & - \\
\hline Other & 77 & $1.78(0.98-3.25)$ & $2.08(1.13-3.84)$ & - \\
\hline \multicolumn{5}{|c|}{ Level of surgery ${ }^{a}$} \\
\hline Minor & 394 & 1 & 1 & 1 \\
\hline Major & 267 & $1.55(1.26-1.91)$ & $1.54(1.25-1.90)$ & $1.26(1.01-1.57)$ \\
\hline
\end{tabular}

${ }^{a}$ Major $=$ above the ankle or above the wrist; minor $=$ hand, foot or part thereof.

$R R=$ relative risk; $a R R=$ adjusted relative risk; $C I=$ confidence interval .

diabetes-related rates found in Scotland ( 1.5 per 10000 in 2006, in a population with diabetes prevalence of 3.8\%) [12], even though the prevalence of diabetes is likely to be higher in Lebanon (13.7\% in 1995) [13]. In a previous study, differences in the known prevalence of diabetes did not account for the differences in overall amputation rates between centres [10]. Amputation rates were thought to be more significantly related to the availability of health care and the incidence of vascular disease. A wide variation in the incidence of amputation exists between populations owing to the medical, cultural and social factors involved, along with the structure of health care services and attitudes of health professionals [11]. Due to the multitude of contextual factors involved there are few recommendations for an appropriate amputation rate.

There is some suggestion that the incidence of amputation in Lebanon may have increased from 0.46 in 2001-05 to 1.59 per 10000 population in this study in 2007 (Table 5) [5]. However, differences in sample selection, measurement and response rates may also explain these results. Reflecting this, the apparent increase in amputation surgery occurred across all indications. Changes in health service provision or in the practice of health professionals may also have contributed.

The rate of amputation may be up to 3-fold higher in southern Lebanon than in Beirut or Mount Lebanon areas and the higher rate was evident for all indications. Political instability, challenges to health service provision and poor socioeconomic conditions in the south of Lebanon [14], or a rebound from these factors, may contribute. In 2006, thousands of cluster bombs were dropped in the area, and there are an estimated 0.5 to 1 million unexploded submunitions. In addition to the destruction of infrastructure, residential buildings and health care centres, the impact of unexploded cluster bombs is thought to be felt for years to come, obstructing economic and social development [15]. During an assessment of affected health facilities carried out by the Lebanese MoPH and the World Health Organization in 2006, $26 \%$ of all health facilities in the area were not operating due to destruction, inaccessibility or deficient staff numbers, and electricity shortages, medical supplies and water supply were major problems preventing health service delivery [16]. Valuable education and screening for diabetics at risk of foot ulcers may have been relegated in priority, especially with the shortage in medical services and supplies. Further research should aim to clarify the etiology of higher amputation rates in the south and the distribution of other diabetic complications. There are little data available on the distribution of neuropathy, retinopathy and nephropathy in Lebanon.

\section{Indications}

Diabetes was the main indication for amputation (59\%), followed by vascular disease (18\%). Our results show that the diabetes-related amputation rate may have increased from 0.28 per 10000 persons in 2001-05 [5] to 0.94 per 10000 in 2007 (Table 5). This may reflect an increasing prevalence and severity of diabetes in Lebanon or a difference in study methodology. Furthermore, poor control and high prevalence of vascular complications has been demonstrated in adult patients with type 2 diabetes in Lebanon and in neighbouring regions $[17,18]$.

Management of diabetes in neighbouring Arab states of the Gulf Region has been described as suboptimal $[4,18]$ and similarly in Lebanon primary care is not well developed. Many of those who provide such services are not fully trained as family physicians. The diagnosis and the management of the diabetic foot are sometimes insufficient. Yet foot problems can be 


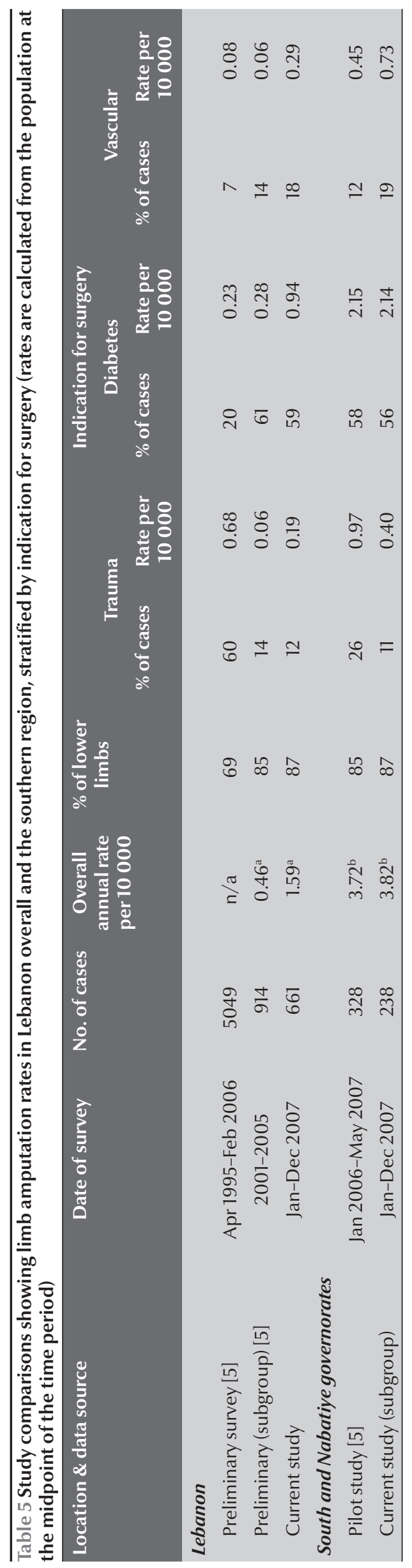

largely preventable through simple foot care, and diabetic patients should have regular foot checks. The large majority of type 2 diabetes should be possible to prevent [19] and a multidisciplinary approach to foot care has been shown to play an important role in reducing rates of major amputation in diabetic patients [20].

The risk factors for both diabetes and vascular disease closely overlap. Obesity rates and cigarette smoking are increasing among the Lebanese population [21]. The prevalence of obesity in 2003 was about $19 \%$ for women and $14 \%$ for men, and the prevalence of overweight was $49.4 \%$ and $57.7 \%$ respectively, similar to rates observed in developed countries. The most obese were those less educated, just as higher rates of type 2 diabetes have been demonstrated in low socioeconomic groups in Lebanon [2]. Addressing risk factors such as body mass index, smoking, nutrition and physical activity will reduce cardiovascular disease and slow the progression to vasculopathy. This is especially important for the diabetic patient. A comprehensive approach to preventing, detecting and managing diabetes is urgently required.

Our figures for trauma, which accounted for $6 \%$ of major amputation surgeries, are consistent with a multicentre study in 2000, where trauma accounted for less than $10 \%$ of major amputations in $9 / 10$ centres [10]. In the Islamic Republic of Iran, $87 \%$ of trauma-related amputation patients in 2000-04 were men and the mean age was 29 years [22], virtually equivalent to our results ( $86 \%$ males and mean age 30 years). Trauma-related amputations included war, mines, road traffic and occupational accidents. Road traffic accidents are an important public health issue in Lebanon as they may be in countries such as the Islamic Republic of Iran. More than 350 individuals die every year in Lebanon from car accidents and people aged 15-40 years are the most affected [23].

The Lebanese-Israeli conflict in July 2006 was expected to push the main indication for amputation further towards trauma. Although this was not the case, it is still possible that the consequences of war may not appear in the amputation statistics until later years. Landmines are known to be a major cause of trauma indicating amputation and many 10000 s to 100000 s of cluster bomb submunitions are reported to have been dropped over southern Lebanon [5].

\section{Major level surgery}

Lower extremity amputations constituted $87 \%$ of all amputations and occurred mostly in the foot and lower leg, reflecting the pathology of diabetes. These findings are consistent with previous studies of amputation in Lebanon (Table 5). Also the 37\% rate of major amputation for diabetes patients was similar to the $41 \%$ found in England [1]. The importance of diabetes and vascularrelated amputations was demonstrated with evidence that these patients had significantly greater rates of major surgery (adjusted $\mathrm{OR}=7.87$ and $\mathrm{OR}=46.3$ respectively). 


\section{Length of hospital stay}

Patients with diabetes and vascular indications had much longer hospital stays compared with patients with trauma-related amputation (adjusted $\mathrm{RR}=4.56$ and 6.33 respectively). Independent of indication, age and sex, patients with major surgery had a statistically significant estimated $26 \%$ longer hospital stay. Our results are consistent with the longer hospital stay among diabetes-related lower extremity amputations in England compared with patients without diabetes [1].

The mean length of hospital stay in Lebanon after amputation (10.1 days) was much less than the mean 61.7 days found in Australia [24]. This may indicate varying approaches of different health systems to rehabilitation.

\section{Conclusions}

Diabetes and vascular indications were not only more common than trauma-related amputation, but both were associated with more major surgery and longer hospital stays. These factors must be considered when assessing the burden of disease for amputation, especially when looking for the best ways to alleviate this burden and improve health services. The development of health policies for diabetes prevention and education should target those most at risk, including the less educated and those living in challenging political and sociocultural environments such as southern Lebanon.

\section{Acknowledgements}

No specific funding was attained for this paper. The analysis originated from the thesis of Ms Kinda Yaghi carried out at Imperial College London and supervised by Professor Rawaf. Dr Yasser Yaghi is an orthopaedic surgeon at Hammoud Hospital University Medical Center in Saida, Lebanon. Dr Andrea McDonald, Ms Elizabeth Dubois and Ms Elizabeth Cecil are researchers in the WHO Collaborating Centre for Public Health Education and Training and the Department of Primary Care and Public Health, Imperial College London. Dr Ghasem Yadegarfar is a statistician and Professor Azeem Majeed is the head of department. The department is grateful for support from the NIHR Collaboration for Leadership in Applied Health Research and Care (CLAHRC) Scheme, the NIHR Biomedical Research Centre scheme, and the Imperial Centre for Patient Safety and Service Quality.

\section{References}

1. Vamos EP et al. Trends in lower extremity amputations in people with and without diabetes in England, 1996-2005. Diabetes Research and Clinical Practice, 2010, 87:275-282.

2. Salti IS et al. Epidemiology of diabetes mellitus in relation to other cardiovascular risk factors in Lebanon. Eastern Mediterranean Health Journal, 1997, 3:462-470.

3. King H, Aubert RE, Herman WH. Global burden of diabetes, 1995-2025: prevalence, numerical estimates, and projections. Diabetes Care, 1998, 21:1414-1431.

4. Alhyas L et al. Prevalences of overweight, obesity, hyperglycaemia, hypertension and dyslipidaemia in the Gulf: systematic review. Journal of the Royal Society of Medicine Short Reports, 2011, 2(7):55.

5. Yaghi Y. A survey on amputation in Lebanon. Beirut, Bone and Joint Decade, National Action Network Lebanon and United Nations Economic and Social Commission for Western Asia, 2006 (http://www.boneandjointdecade.org/Default. aspx? contld=294, accessed 12 September 2012).

6. Bone and Joint Decade 2000-2010. InfoLetter 56. Bone and Joint Decade [newsletter] (http://www.boneandjointdecade.org/ HTML/musconline/images/infoletters/Infoletter_56.pdf, accessed 12 September 2012).

7. Ammar W, Wakim IR, Hajj I. Accreditation of hospitals in Lebanon: a challenging experience. Eastern Mediterranean Health Journal, 2007, 13:138-149.

8. Statistics. United Nations Food and Agriculture Organization [online database] (http://faostat.fao.org/, accessed 12 September 2012).

9. Chapitre 1. La struture demographique. Beirut, Central Administration for Statistics, Ministry of Social Affairs Lebanon and United Nations Development Fund, 2004-05 (http://www. localiban.org/IMG/pdf/La_Structure_Demographique_Libanaise.pdf, accessed 12 September 2012).
10. Group TGLEAS; Global Lower Extremity Amputation Study Group. Epidemiology of lower extremity amputation in centres in Europe, North America and East Asia. British Journal of Surgery, 2000, 87:328-337.

11. Jeffcoate WJ, van Houtum WH. Amputation as a marker of the quality of foot care in diabetes. Diabetologia, 2004, 47:2051-2058.

12. Schofield CJ et al. Decreasing amputation rates in patients with diabetes-a population-based study. Diabetic Medicine, 2009, 26:773-777.

13. King H, Aubert RE, Herman WH. Global burden of diabetes, 1995-2025: prevalence, numerical estimates, and projections. Diabetes care. 1998, 21(9):1414-1431.

14. Cornec M. Poverty map. Beirut, Al Majmoua, Lebanese Association for Development, 2004.

15. A lasting legacy: the deadly impact of cluster bombs in southern Lebanon. Lebanon, United Nations Office for the Coordination of Humanitarian Affairs, 2006 (http://www.mineaction. org/downloads/1/OCHA_lasting\%20legacy.pdf, accessed 12 September 2012).

16. Lebanon health facilities have suffered considerable damage. Press release, 6 September 2006. Geneva, World Health Organization, 2006 (http://www.who.int/hac/crises/international/ middle_east/Lebanon_2Sept2006/en/index.html, accessed 17 September 2012).

17. Taleb $\mathrm{N}$ et al. Vascular complications of diabetes in Lebanon: Experience at the American University of Beirut. British Journal of Diabetes and Vascular Disease, 2008, 8:80-83.

18. Alhyas $L$ et al. Quality of type 2 diabetes management in the states of the Co-operation Council for the Arab States of the Gulf: a systematic review. PLoS ONE, 2011, 6:e22186.

19. Zimmet $\mathrm{P}$, Alberti KG, Shaw J. Global and societal implications of the diabetes epidemic. Nature, 2001, 414:782-787. 
20. Larsson J et al. Decreasing incidence of major amputation in diabetic patients: a consequence of a multidisciplinary foot care team approach? Diabetic Medicine, 1995, 12:770-776.

21. Sibai AM et al. Prevalence and covariates of obesity in Lebanon: findings from the first epidemiological study. Obesity, 2003, 11:1353-1361.

22. Moini M et al. Patterns of extremity traumas leading to amputation in Iran: results of Iranian National Trauma Project. Chinese Journal of Traumatology, 2009, 12:77-80.
23. Injury and accident prevention program. YASA [online] (http:// www.yasa.org/en/Sectiondet.aspx?id=10\&id2=546, accessed 17 October 2012).

24. Lim TS et al. Outcomes of a contemporary amputation series. Australian and New Zealand Journal of Surgery, 2006, 76:300-305.

\section{Prevention and control of noncommunicable diseases: guidelines for primary health care in low resource settings}

The primary goal of Prevention and control of noncommunicable diseases: guidelines for primary health care in low resource settings is to improve the quality of care and the outcome in people with type 2 diabetes in low-resource settings. The guideline provides a basis for development of simple algorithms for management of diabetes with essential medicines and technology available in first-contact health services in low-resource settings. It recommends a set of basic interventions to integrate management of diabetes into primary health care. The recommendations are limited to patients with type 2 diabetes, as the more complex management of type 1 diabetes requires more specialized care.

The target users are health care professionals responsible for developing diabetes treatment protocols which will be used by health care staff in primary care units in low-resource settings. A guideline development group was constituted, which included external experts and WHO staff.

Further information about this and other WHO publications is available at: http://www.who.int/publications/en/ 